\title{
KINEMATIC FUNDAMENTALS FOR THE SEMI-AUTOMATED DRILLING OF VERTICAL BLAST HOLES IN SALT MINES
}

\author{
Prof. Dr.-Ing. J. Hesselbach ${ }^{A}$, Prof. Dr.-Ing. N. Plitea ${ }^{B}$, \\ Dr.-Ing. M. Walter ${ }^{C}$, Dipl.-Ing. C. Reekers ${ }^{A}$ \\ A Institute of Machine Tools and Production Engineering, TU Braun- \\ schweig, Germany, B Institute of Parallel Structures and Parallel Robots, \\ TU Cluj-Napoca, Romania, ${ }^{C}$ BTZ Dietlas GmbH, Germany
}

\begin{abstract}
To increase the accuracy of drilling in salt diapir a software module with kinematic equations was integrated into the control of a drilling vehicle. Despite the complex hybrid serial-parallel structure the HD-notation is used for the kinematic equations. DKP and IKP (with the method of Paul) are calculated analytically. The undefined ceiling of the tunnel requires a semi-automated operation which is enabled by a combination of DKP and IKP. Since reference points are unknown, a method was developed in which the reference points lie in a defined position to each other and to the reference system.
\end{abstract}

Keywords: Drilling vehicle, blast holes, salt mines, HD-notation, methods of Paul

\section{INTRODUCTION}

According to the drilling scheme shown below (Figure 1), blast holes $P_{i}$ are drilled with the aid of a drilling vehicle to extract salt vertically. The height of the boreholes can be up to $100 \mathrm{~m}$. To blast the salt in an optimal way angle $\alpha$ transverse the salt diapir and angle $\beta$ along the salt diapir have to be kept within certain given limits. On account of the handicaps of the Mining Office, the width must not exceed $40 \mathrm{~m}$.

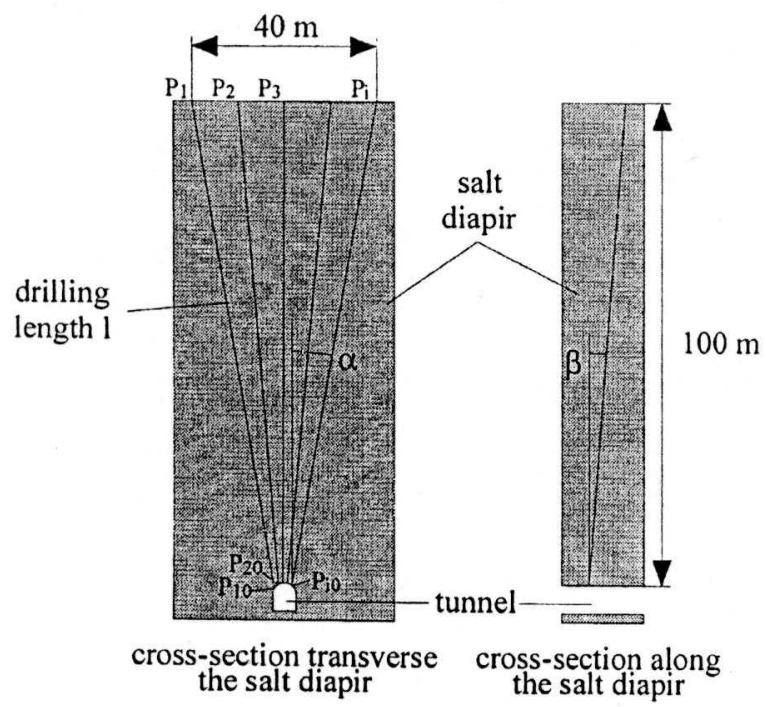

Figure 1: Drilling scheme

To drill these blast holes $\mathrm{P}_{\mathrm{i}}$ a drilling vehicle was designed which is shown in Figure 2.

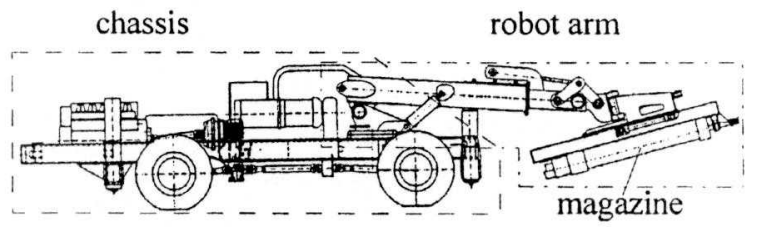

Figure 2: Design of the drilling vehicle

The drilling vehicle can be divided into two main modules: the chassis and the robot arm with the magazine holder. In this magazine the drilling bars are stored. These drilling bars have to be composed automatically by an operator until the desired drilling length 1 is reached.

To drill the boreholes according to the scheme described above the top of the magazine holder has to correspond to point $\mathrm{P}_{\mathrm{i} 0}$, the orientation of the magazine holder has to correspond to the angles $\alpha$ und $\beta$. When the drilling bars are extended to the drilling length $I$ the point $P_{i}$ is reached.

In the case of a previous drilling vehicle design the robot arm and the magazine holder were adjusted by the operator. So the experience of the operator determines the accuracy. To increase the accuracy of the angles $\alpha$ and $\beta$ and of the position $P_{i}$ a new design of the drilling vehicle was developed. The robot arm and the magazine holder of this new vehicle now can be moved semiautomated. The semi-automated operation is possible because of a control that includes a software-modul based on the following considerations. 


\section{KINEMATICS OF THE DRILLING VEHICLE}

\subsection{Movement possibilities}

The kinematic structure of the robot arm and of the magazine holder can be divided into serial and parallel subchains which lie in two different planes (Figure 3).

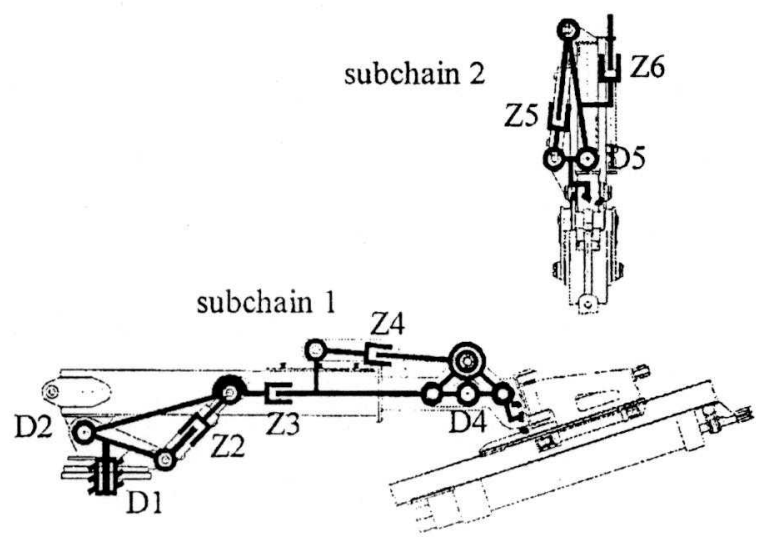

Figure 3: Kinematic structure

These subchains consist exclusively of rotary and prismatic joints and form planar mechanisms individually. The joints have one degree of freedom $\left(f_{i}=1\right)$ :

$$
\begin{aligned}
\mathrm{F}_{\text {plane } 1}= & \mathrm{F}_{\text {plane } 2}=3 \cdot(\mathrm{n}-\mathrm{g}-1)+\sum \mathrm{f}_{\mathrm{i}}-\mathrm{f}_{\mathrm{id}} \\
\text { with } \quad \mathrm{n}: \text { number of links } & \mathrm{g} \text { : number of joints } \\
& \sum \mathrm{f}_{\mathrm{i}}: \text { sum of the degrees of freedom } \\
& \mathrm{f}_{\mathrm{id}} \text { : identical degrees of freedom }
\end{aligned}
$$

plane $1: n=9$

$$
\begin{aligned}
& \text { plane 2: } n=5 \\
& \mathrm{~g}=5 \\
& \Sigma \mathrm{f}_{\mathrm{i}}=5 \\
& \mathrm{f}_{\mathrm{id}}=0 \\
& \mathrm{~F}_{\text {plane 2 }}=2
\end{aligned}
$$$$
\mathrm{g}=10
$$$$
\Sigma \mathrm{f}_{\mathrm{i}}=10
$$$$
\mathrm{f}_{\mathrm{id}}=0
$$$$
\mathrm{F}_{\text {plane } 1}=4
$$

$\mathrm{F}_{\text {total }}=\mathrm{F}_{\text {plane 1 }}+\mathrm{F}_{\text {plane 2 }}=6$

Consequently, each point within the range of the drilling vehicle can be reached in any orientation of the magazine holder, e. g. robot arm and magazine holder can be moved as follows:

\begin{tabular}{|l|c|c|}
\hline Movement & rotary joint & elevating ram \\
\hline Swing robot arm & D1 & - \\
\hline Lift/lower robot arm & D2 & Z2 \\
\hline Telescope robot arm & - & $\mathrm{Z3}$ \\
\hline $\begin{array}{l}\text { Lift/lower magazine } \\
\text { holder }\end{array}$ & $\mathrm{D} 4$ & $\mathrm{Z} 4$ \\
\hline Swing magazine holder & $\mathrm{D} 5$ & $\mathrm{Z} 5$ \\
\hline $\begin{array}{l}\text { Telescope magazine } \\
\text { holder }\end{array}$ & - & $\mathrm{Z} 6$ \\
\hline
\end{tabular}

The parallel subchains serve merely to transform the translation of the elevating rams $\mathrm{Z2}, \mathrm{Z} 4$ and $\mathrm{Z} 5$ into a rotation of the rotary joint $\mathrm{Di}$ with corresponding force amplification. Since a rotationally symmetrical drilling tool is at the top of the magazine holder, a degree of freedom of $F=5$ would be sufficient for drilling. For example the movement of the elevating ram $\mathrm{Z} 6$ is not necessary.

\subsection{Calculation of the position and of the orientation of the magazine holder depending on the axis coordi- nates (Direct Kinematic Problem DKP)}

Since the parallel subchains have no effect on the kinematics of the vehicle, they can be neglected. Therefore, the kinematics of the drilling vehicle can be represented as in Figure 4.

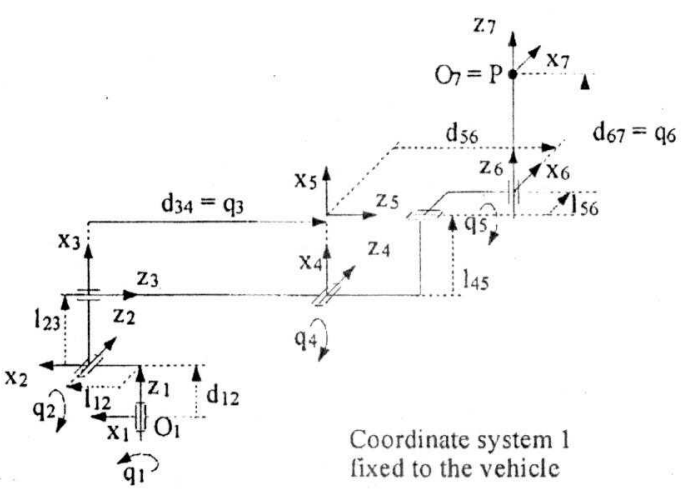

Figure 4: HD-notation of the drilling vehicle

The rotary and prismatic joints of the drilling vehicle are equipped with measuring systems. These systems measure the angles and positions of the axis coordinates q. Using the measurement results the general positi-

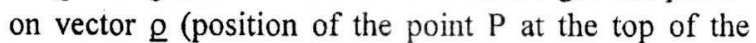
magazine holder and orientation of the magazine holder) can be calculated referring to the coordinate system 1 fixed to the vehicle:

$\underline{\rho}=\left[x_{p}, y_{p}, z_{p}, \psi_{p}, \vartheta_{P}, \varphi_{p}\right]^{T}=f(\underline{q})$

with $\quad \underline{q}=\left[q_{1}, q_{2}, q_{3}, q_{4}, q_{5}, q_{6}\right]^{T}$

and $\quad \psi_{\mathrm{P}}, \vartheta_{\mathrm{P}}, \varphi_{\mathrm{P}}$

$\psi_{\mathrm{P}}, \vartheta_{\mathrm{P}}, \varphi_{\mathrm{P}}$ are the Euler angles (rotation around the $z-, x$ - and z-axis).

The HD-notation [2] is applied to get the solution:

$$
\begin{aligned}
& { }^{1} \underline{\underline{H}}_{\mathrm{p}}={ }^{1} \underline{\underline{H}}_{7}=\prod_{\mathrm{i}=1}^{6}{ }^{\mathrm{i}} \underline{\mathrm{H}}_{\mathrm{i}+1}\left(\mathrm{q}_{\mathrm{i}}\right)=\left[\begin{array}{cc}
{ }^{\mathrm{R}} \underline{\underline{\mathrm{R}}} 7 & { }^{\mathrm{I}} \underline{\mathrm{O}}_{1} \mathrm{P} \\
\underline{0}^{\mathrm{T}} & 1
\end{array}\right] \\
& { }^{1} \underline{\mathrm{H}}_{2}\left(\mathrm{q}_{1}\right) \cdot{ }^{2} \underline{\mathrm{H}}_{3}\left(\mathrm{q}_{2}\right) \cdot \ldots \cdot{ }^{6} \underline{\mathrm{H}}_{7}\left(\mathrm{q}_{6}\right)
\end{aligned}
$$

with $\quad{ }^{1} \mathrm{R}_{7}$ : rotaton matrix

Iolp: translation vector 
and

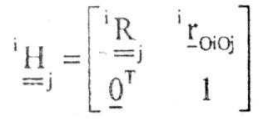

$$
\begin{aligned}
& =\left[\begin{array}{cccc}
\cos \delta_{i j} & -\sin \delta_{i j} \cdot \cos \lambda_{i j} & \sin \delta_{i \mathrm{i}} \cdot \sin \lambda_{\mathrm{ij}} & \mathrm{l}_{\mathrm{ij}} \cdot \cos \delta_{\mathrm{ij}} \\
\sin \delta_{\mathrm{ij}} & \cos \delta_{\mathrm{ij}} \cdot \cos \lambda_{\mathrm{ij}} & -\cos \delta_{\mathrm{ij}} \cdot \sin \lambda_{\mathrm{ij}} & \mathrm{l}_{\mathrm{ij}} \cdot \sin \delta_{\mathrm{ij}} \\
0 & \sin \lambda_{\mathrm{ij}} & \cos \lambda_{\mathrm{ij}} & \mathrm{d}_{\mathrm{ij}} \\
0 & 0 & 0 & 1
\end{array}\right]
\end{aligned}
$$

The HD-notation supplies the position ${ }^{1}$ rolp of the point $\mathrm{P}$ at the top of the magazine holder and orientation ${ }^{1} \underline{R}_{7}$ of the magazine holder.

\subsection{Calculation of the axis coordinates depending on the position and orientation of the magazine holder (Inverse Kinematic Problem IKP)}

If the drilling operation shall be carried out fully automatically, the position ( $\left.{ }^{1} \underline{r}_{01 P}\right)$ and the orientation $\left({ }^{1} \underline{R}_{7}\right)$ of the magazine holder can be pre-set. Since the distance for the 6th axis has not to be calculated (see 2.1), the measured value of this axis is constant in the calculation.

Given:

$$
x_{p}, y_{p}, z_{P}, \psi_{p}, \vartheta_{p}, q_{6}
$$

Besides of the axis coordinates $q_{1} \ldots q_{5}$ the angle of orientation $\varphi_{p}$ has to be calculated:

Unknown: $\quad q_{1}, q_{2}, q_{3}, q_{4}, q_{5}, \varphi_{P}$

Using equation

$$
\stackrel{{ }^{\prime}}{=} \mathrm{P}=\left[\begin{array}{cccc}
\alpha^{\prime} & \alpha^{\prime \prime} & \alpha^{\prime \prime \prime} & \mathrm{x}_{\mathrm{p}} \\
\beta^{\prime} & \beta^{\prime \prime} & \beta^{\prime \prime \prime} & \mathrm{y}_{\mathrm{p}} \\
\gamma^{\prime} & \gamma^{\prime \prime} & \gamma^{\prime \prime \prime} & \mathrm{z}_{\mathrm{p}} \\
0 & 0 & 0 & 1
\end{array}\right]={ }^{1} \underline{\underline{H}}_{2}\left(\mathrm{q}_{1}\right) \cdot \ldots \cdot{ }^{6} \underline{\underline{H}}_{7}\left(\mathrm{q}_{6}\right)(1)
$$

$\alpha^{\prime}, \alpha^{\prime \prime}, \ldots, \gamma^{\prime \prime}, \gamma^{\prime \prime \prime}$ depend on the Euler angles $\psi_{\mathrm{P}}, \vartheta_{\mathrm{P}}$ (given) and the orientation angle $\varphi_{P}$ (unknown). Eq. (1) can be written as

$$
{ }^{1} \underline{\mathrm{H}}_{\mathrm{P}}=\left[\begin{array}{cccc}
\mathrm{m} \cdot \mathrm{c} \varphi_{\mathrm{P}}+\mathrm{n} \cdot \mathrm{s} \varphi_{\mathrm{P}} & -\mathrm{m} \cdot \mathrm{s} \varphi_{\mathrm{P}}+\mathrm{n} \cdot \mathrm{c} \varphi_{\mathrm{P}} & \alpha^{\prime \prime \prime} & \mathrm{x}_{\mathrm{P}} \\
\mathrm{p} \cdot \mathrm{c} \varphi_{\mathrm{P}}+\mathrm{r} \cdot \mathrm{s} \varphi_{\mathrm{P}} & -\mathrm{p} \cdot \mathrm{s} \varphi+\mathrm{r} \cdot \mathrm{c} \varphi_{\mathrm{P}} & \beta^{\prime \prime \prime} & \mathrm{y}_{\mathrm{P}} \\
\mathrm{d} \cdot \mathrm{s} \varphi_{\mathrm{P}} & \mathrm{d} \cdot \mathrm{c} \varphi_{\mathrm{P}} & \gamma^{\prime \prime \prime} & \mathrm{z}_{\mathrm{P}} \\
0 & 0 & 0 & 1
\end{array}\right]
$$

with

$$
\begin{array}{ll}
\mathrm{c} \varphi_{\mathrm{P}}=\cos \varphi_{\mathrm{P}} & \mathrm{s} \varphi_{\mathrm{P}}=\sin \varphi_{\mathrm{P}} \\
\mathrm{m}=\cos \psi_{\mathrm{P}} & \mathrm{n}=-\sin \psi_{\mathrm{P}} \cdot \cos \vartheta_{\mathrm{P}} \\
\mathrm{p}=\sin \psi_{\mathrm{P}} & \mathrm{r}=\cos \psi_{\mathrm{P}} \cdot \cos \vartheta_{\mathrm{P}} \\
\mathrm{d}=\sin \vartheta_{\mathrm{P}} & \\
\alpha^{\prime \prime \prime}=\sin \psi_{\mathrm{P}} \cdot \sin \vartheta_{\mathrm{P}} & \boldsymbol{\beta}^{\prime \prime \prime}=-\cos \psi_{\mathrm{P}} \cdot \sin \vartheta_{\mathrm{P}} \\
\gamma^{\prime \prime \prime}=\cos \vartheta_{\mathrm{P}} &
\end{array}
$$

Since the axis coordinate $\mathrm{q}_{6}$ is given and coordinate system 6 has the same orientation as coordinate system 7 Eq. (1) with Eq. (2) can be simplified:

$$
\begin{aligned}
& { }^{\prime} \mathrm{H}_{6}=\left[\begin{array}{cccc}
m \cdot c \varphi_{p}+n \cdot s \varphi_{p} & -m \cdot s \varphi_{P}+n \cdot c \varphi_{p} & \alpha^{\prime \prime \prime} & x_{06} \\
p \cdot c \varphi_{P}+r \cdot s \varphi_{p} & -p \cdot s \varphi+r \cdot c \varphi_{p} & \beta^{\prime \prime \prime} & y_{06} \\
d \cdot s \varphi_{p} & d \cdot c \varphi_{p} & \gamma^{\prime \prime \prime} & z_{06} \\
0 & 0 & 0 & 1
\end{array}\right] \\
& ={ }^{1} \underline{\underline{H}}_{2}\left(q_{1}\right) \cdot{ }^{2} \underline{H}_{3}\left(q_{2}\right) \cdot{ }^{3} \underline{H}_{4}\left(q_{3}\right) \cdot{ }^{4} \underline{H}_{5}\left(q_{4}\right) \cdot{ }^{5} \underline{\underline{H}}_{6}\left(q_{5}\right) \\
& \text { with } x_{06}=x_{p^{\prime}}-q_{6} \cdot \alpha^{\prime \prime \prime} \quad y_{06}=y_{p}-q_{6} \cdot \beta^{\prime \prime \prime} \\
& z_{06}=z_{p}-q_{6} \cdot \gamma^{\prime \prime \prime}
\end{aligned}
$$

The method of Paul [2] is used for the solution. Due to this method Eq. (3) is varied by multiplication with the inverse matrices:

$$
\begin{aligned}
& { }^{1}{ }_{=}^{\mathrm{H}}\left(\varphi_{\mathrm{P}}\right)={ }^{1}{ }_{=}^{\mathrm{H}}\left(\mathrm{q}_{1}\right) \cdot{ }^{2} \underline{\underline{H}}_{3}\left(\mathrm{q}_{2}\right) \cdot{ }^{3} \underline{\underline{H}}_{4}\left(\mathrm{q}_{3}\right) \cdot{ }^{4} \underline{\underline{H}}_{5}\left(\mathrm{q}_{4}\right) \cdot{ }^{5} \underline{\underline{H}}_{6}\left(\mathrm{q}_{5}\right) \\
& { }^{\prime} \underline{\underline{H}}_{6}\left(\varphi_{\mathrm{P}}\right) \cdot{ }^{5} \underline{\underline{H}}_{6}^{-1}\left(q_{5}\right)={ }^{1} \underline{\underline{H}}_{2}\left(q_{1}\right) \cdot{ }^{2}{ }_{\underline{H}}{ }_{3}\left(q_{2}\right) \cdot{ }^{3} \underline{\underline{H}}_{4}\left(q_{3}\right) \cdot{ }^{4} \underline{\underline{H}}_{5}\left(q_{4}\right) \\
& { }^{1} \underline{H}_{6}\left(\varphi_{p}\right) \cdot{ }^{5} \underline{H}_{6}^{-1}\left(q_{5}\right) \cdot{ }^{4} \underline{H}_{5}^{-1}\left(q_{4}\right)={ }^{1} \underline{H}_{2}\left(q_{1}\right) \cdot{ }^{2} \underline{\underline{H}}_{3}\left(q_{2}\right) \cdot{ }^{3} \underline{H}_{4}\left(q_{3}\right) \\
& \text { etc. } \\
& { }^{1} \underline{\mathrm{H}}_{2}^{-1}\left(\mathrm{q}_{1}\right) \cdot \underline{\underline{H}}_{6}\left(\varphi_{\mathrm{p}}\right)={ }^{2} \underline{\underline{H}}_{3}\left(\mathrm{q}_{2}\right) \cdot{ }^{3} \underline{\underline{H}}_{4}\left(\mathrm{q}_{3}\right) \cdot{ }^{4} \underline{\underline{H}}_{5}\left(\mathrm{q}_{4}\right) \cdot{ }^{3} \underline{\underline{H}}_{6}\left(\mathrm{q}_{5}\right) \\
& { }^{2} \underline{\mathrm{H}}_{3}^{-1}\left(q_{2}\right) \cdot{ }^{1} \underline{\underline{H}}_{2}^{-1}\left(q_{i}\right) \cdot{ }^{1} \underline{H}_{6}\left(\varphi_{p}\right)={ }^{3} \underline{H}_{4}\left(q_{3}\right) \cdot{ }^{4} \underline{H}_{5}\left(q_{4}\right) \cdot{ }^{5} \underline{H}_{6}\left(q_{5}\right) \\
& \text { etc. } \\
& { }^{\prime} \underline{\underline{H}}_{2}^{-1}\left(q_{1}\right) \cdot \underline{\underline{H}}_{6}\left(p_{p}\right) \cdot{ }^{5} \underline{\underline{H}}_{6}^{-1}\left(q_{5}\right)={ }^{2} \underline{\underline{H}}_{3}\left(q_{2}\right) \cdot{ }^{3} \underline{\underline{H}}_{4}\left(q_{3}\right) \cdot{ }^{4} \underline{\underline{H}}_{5}\left(q_{4}\right) \\
& { }^{\prime} \underline{\mathrm{H}}_{2}^{-1}\left(\mathrm{q}_{1}\right) \cdot{ }_{\underset{m}{\mathrm{H}}}^{\mathrm{H}}\left(\varphi_{\mathrm{P}}\right) \cdot{ }^{5} \mathrm{H}_{=6}^{-1}\left(\mathrm{q}_{5}\right) \cdot{ }^{4} \underline{\mathrm{H}}_{5}^{-1}\left(\mathrm{q}_{4}\right)={ }^{2} \underline{\underline{H}}_{3}\left(\mathrm{q}_{2}\right) \cdot{ }^{3} \underline{\underline{H}}_{4}\left(\mathrm{q}_{3}\right) \\
& \text { etc. }
\end{aligned}
$$

31 different equations result from these multiplications. 12 matrix elements can be compared on both sides of each equation. Those equations which enable an analytical solution are selected from these $12 \times 31=372$ equations.

In the case of the drilling vehicle this analytical solution leads to 16 positions which can be limited by steric conditions, e. $\mathrm{g}$. by the pre-set range of the drilling vehicle.

\section{OPERATING MODES}

The operator can select between two operating modes: the manual operation and the semi-automated fixedpoint operation.

\subsection{Manual operation}

With this operating mode the operator adjusts all axes of the drilling vehicle with remote control. From the current measured values for the axis coordinates $q$ the control calculates the angles $\alpha_{\text {current }}$ and $\beta_{\text {current }}$ using the DKP (see 2.2). If a file with the coordinates of the points $\mathrm{P}_{\mathrm{i}}$ of the drilling scheme is integrated into the control, the current values $\alpha_{\text {current }}$ and $\beta_{\text {current }}$ can be compared directly with the the reference values $\alpha_{\text {reference }}$ and $\beta_{\text {reference. }}$ If it is necessary the operator can correct the axes. 


\subsection{Semi-automated fixed-point}

Using the IKP (see 2.3) the axis coordinates $g$ can be moved fully automatically, if the points $\mathrm{P}_{\mathrm{i}}$ or $\mathrm{P}_{\mathrm{i} 0}$ and the angles $\alpha$ and $\beta$ are given. For safety reasons the drilling vehicle must not be operated full-automated, since the steric conditions of the tunnel limit the operation. Therefore, a semi-automated so-called fixed-point operation was integrated instead of a full-automated operation.

The fixed-point operation requires a file with the points $P_{i}$ of a drilling scheme. This file has to be integrated into the control.

The operator sets up the four axes with remote control:

- Swing robot arm $\left(\mathrm{q}_{1}\right)$

- Lift/lower robot arm $\left(\mathrm{q}_{2}\right)$

- Telescope robot arm $\left(\mathrm{q}_{3}\right)$

- Telescope magazine holder $\left(q_{6}\right)$

From the current measured values of the four axes and from the given position of point $\mathrm{P}_{\mathrm{i}}$ the control computes the necessary angles for

- lift/lower magazine holder $\left(q_{4}\right)$ and

- swing magazine holder $\left(\mathrm{q}_{5}\right)$.

The control adjusts automatically these two angles. The current values $\alpha_{\text {current }}$ and $\beta_{\text {current }}$ can be compared directly with the the reference values $\alpha_{\text {reference }}$ and $\beta_{\text {reference. }}$ If it is necessary the operator can correct the four axes.

Figure 5 clarifies the computations practised in the control:

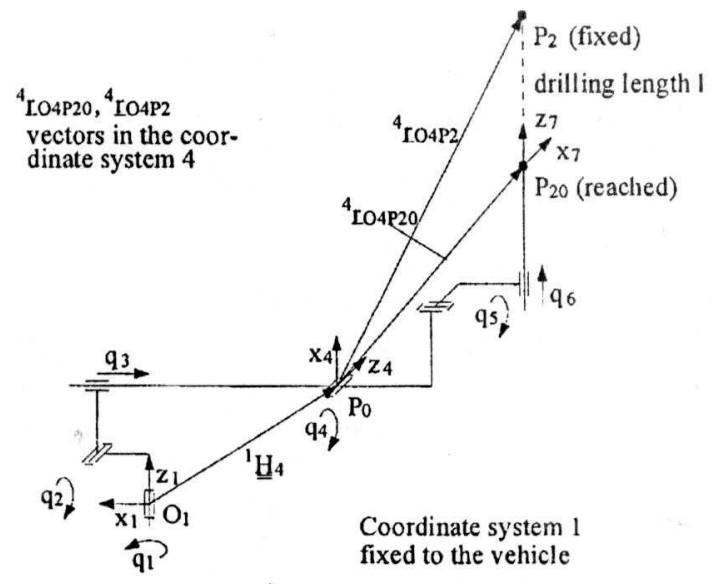

Figure 5: Fixed-point operation

The position ' ${ }^{1} \mathrm{O}_{04}$ and the orientation ${ }^{1} \underline{R}_{0104}$ of the origin $\mathrm{O}_{4}$ can be calculated with the given angles and positions $\mathrm{q}_{1}, \mathrm{q}_{2}$ and $\mathrm{q}_{3}$ :

${ }^{1} \underline{\underline{H}}_{4}=f\left(q_{1}, q_{2}, q_{3}\right) \quad$ (see DKP, 2.2$)$

The coordinates of the fixed point $\mathrm{P}_{2}$ are given in coordinate system 1 . These coordinates can be transformed into coordinate system 4 :
${ }^{1} \underline{\mathrm{r}}_{\mathrm{P} 2}={ }^{1} \underline{\mathrm{r}}_{0104}+{ }^{1} \underline{\mathrm{r}}_{04 \mathrm{P2}}={ }^{1} \underline{\mathrm{r}}_{0104}+{ }^{1} \underline{\underline{H}}_{4} \cdot{ }^{4} \underline{\mathrm{r}}_{04 \mathrm{P} 2}$

The direction of the magazine holder corresponds to the orientation of the ${ }^{7} \mathrm{z}_{7}$-axis in coordinate system 7 at the top of the magazine holder.

In coordinate system 4 the following Eq. (5) results for the position ${ }^{4} \underline{\mathrm{O}}_{04 \mathrm{P} 2}$ and the orientation ${ }^{4} \mathrm{R}_{\mathrm{O}} \mathrm{P} 20$ of point $P_{20}$ at the top of the magazine holder:

$$
\begin{aligned}
& { }^{4}{ }_{7}={ }^{4} \underline{\mathrm{H}}_{5} \cdot{ }^{5} \underline{\mathrm{H}}_{6} \cdot{ }^{6} \underline{\underline{H}}_{7}=\left[\begin{array}{cccc}
\bullet & \bullet & \alpha^{\prime \prime \prime} & { }^{4} \mathrm{x}_{\mathrm{P} 20} \\
\bullet & \bullet & \beta^{\prime \prime \prime} & { }^{4} \mathrm{y}_{\mathrm{P} 20} \\
\bullet & \bullet & \gamma^{\prime \prime \prime} & { }^{4} \mathrm{z}_{\mathrm{P} 20} \\
0 & 0 & 0 & 1
\end{array}\right] \\
& \text { direction of }{ }^{4} z_{7} \quad{ }^{4} \underline{r}_{04 \mathrm{P} 20}
\end{aligned}
$$

with $\quad \alpha " \prime, \beta ",, \gamma^{\prime \prime \prime}=f\left(q_{4}, q_{5}\right)$

and $\quad{ }^{4} \underline{\mathrm{r}}_{04 \mathrm{p} 20}=\mathrm{f}\left(\mathrm{q}_{4}, \mathrm{q}_{5}, \mathrm{q}_{6}\right)$

With this we get

$$
\begin{gathered}
{ }^{4} \underline{\mathrm{r}}_{\mathrm{O} 4 \mathrm{P} 2}={ }^{4} \underline{\mathrm{r}}_{04 \mathrm{P} 20}+{ }^{4} \underline{\mathrm{r}}_{\mathrm{P} 20 \mathrm{P} 2}= \\
{\left[\begin{array}{c}
{ }^{4} \mathrm{x}_{\mathrm{P} 20} \\
{ }^{4} \mathrm{y}_{\mathrm{P} 20} \\
{ }^{4} \mathrm{z}_{\mathrm{P} 20}
\end{array}\right]+\lambda \cdot\left[\begin{array}{l}
\alpha \\
\alpha^{\prime \prime \prime} \\
\beta^{\prime \prime \prime} \\
\gamma^{\prime \prime \prime}
\end{array}\right]={ }^{1} \underline{\mathrm{H}}_{4}^{-1} \cdot{ }^{1} \underline{\mathrm{r}}_{04 \mathrm{P} 2}}
\end{gathered}
$$

Eq. (5) and Eq. (6) lead to the solution for $q_{4}, q_{5}$ and $\lambda$. $\lambda$ is simultanously the drilling length 1 (distance between the top of the magazine holder $\mathrm{P}_{20}$ and point $\mathrm{P}_{2}$ ).

\section{REFERENCE POINTS}

The coordinates of the points $P_{j}$ which have to be drilled are stored in a file. These coordinates refer to coordinate system 0 of the drilling scheme. However, the position and orientation of the drilling vehicle in coordinate system 0 is unknown. Therefore, the position and orientation of the vehicle $\left(\mathrm{O}_{1}\right)$ must be calculated in coordinate system 0 of the drilling scheme (Figure 6).

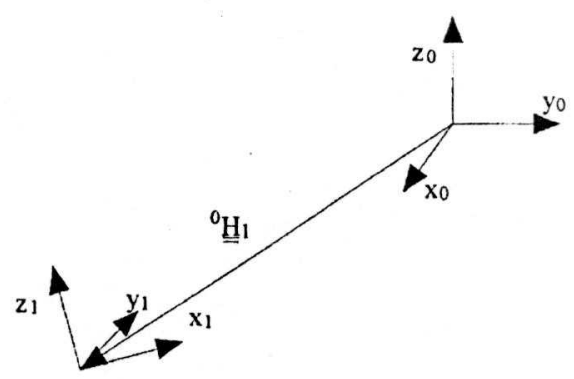

Figure 6: Vehicle-fixed coordinate system 1 and coordinate system 0 of the drilling scheme 
For the calculation of ${ }^{0} \underline{\mathrm{H}}_{1}$ reference points can be used. The positions of these reference points have to be known in the drilling scheme 0 ( $\left.{ }^{0} \underline{r}_{\text {reference point }}\right)$. Furthermore their positions in coordinate system 1 ( ${ }^{1} \mathbf{r}_{\text {reference point }}$ ) can be calculated with the DKP if the axis coordinates $\mathrm{q}$ are measured. Several solutions are possible, e. g.:

- 4 points $A, B, C$ and $D$ are given

$$
\begin{aligned}
& { }^{0} \underline{H}_{1}=\left[\begin{array}{cc}
{ }^{0} \underline{R}_{1} & { }^{0} \underline{r}_{O_{0} O_{1}} \\
\underline{0}^{\mathrm{T}} & 1
\end{array}\right] \\
& =\left[\begin{array}{cccc}
{ }^{0} \underline{r}_{A} & { }^{0} \underline{r}_{C} & { }^{0} \underline{r}_{B} & { }^{0} \underline{r}_{D} \\
1 & 1 & 1 & 1
\end{array}\right] \cdot\left[\begin{array}{cccc}
{ }^{1} \underline{r}_{A} & { }^{1} \underline{r}_{C} & { }^{1} \underline{r}_{B} & { }^{1} \underline{r}_{D} \\
1 & 1 & 1 & 1
\end{array}\right]^{-1}
\end{aligned}
$$

- 3 points $\mathrm{A}, \mathrm{B}, \mathrm{C}$ are given, point $\mathrm{D}$ is give by point $\mathrm{C}$ (reflected at $\overline{\mathrm{AB}}$ )

$$
\begin{aligned}
& { }^{0} \underline{\mathrm{R}}_{1}=\left[\begin{array}{lll}
{ }^{0} \underline{\mathrm{r}}_{\mathrm{AB}} & { }^{0} \underline{\mathrm{r}}_{\mathrm{AC}} & { }^{0} \underline{\mathrm{r}}_{\mathrm{AD}}
\end{array}\right] \cdot\left[\begin{array}{lll}
{ }^{1} \underline{\mathrm{r}}_{\mathrm{AB}} & { }^{1} \underline{\mathrm{r}}_{\mathrm{AC}} & { }^{1} \underline{\mathrm{r}}_{\mathrm{AD}}
\end{array}\right]^{-1} \\
& { }^{0} \underline{\mathrm{r}}_{\mathrm{O}_{0} \mathrm{O}_{1}}={ }^{0} \underline{\underline{r}}_{\mathrm{A}}-{ }^{0} \underline{\underline{\mathrm{R}}}_{1} \cdot{ }^{1} \underline{\underline{r}}_{\mathrm{A}}
\end{aligned}
$$

The disadvantage of these solutions is the fact that the positions of the reference points must be known in coordinate system 0 of the drilling scheme. However, because of the different steric conditions of the tunnel it is not easy to determine such reference points (e.g. at the ceiling of the tunnel) and to move the robot arm in that way that the magazine holder reaches this reference point. Therefore following considerations lead to a solution.

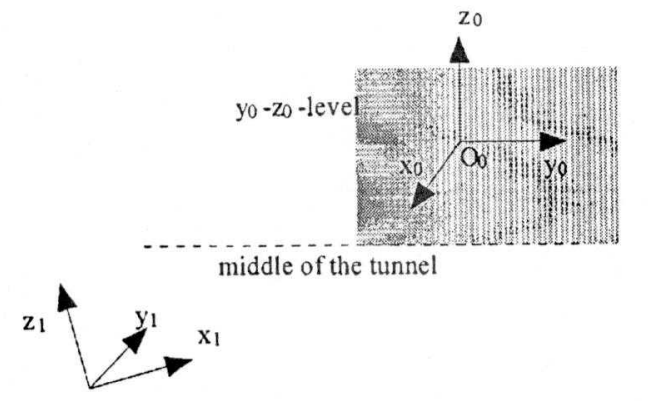

Coordinate system 1 fixed to the vehicle

Figure 7: Origin of coordinate system 0 and the middle of the tunnel

The origin of coordinate system 0 is marked at the ceiling of the tunnel (Figure 7). Also the so-called middle of the tunnel is marked. It is located in the $y_{0}-z_{0}-$ level of the drilling scheme, horizontal and therefore parallel to the $y_{0}$-axis.

We take from that the following (Figure 8):

- The three points A, B and C have to be reached with the magazine holder in vertical orientation. which is enabled by measuring systems and an adequate compensation control.
- The points $\mathrm{A}$ and $\mathrm{B}$ are located in the middle of the tunnel.

- The point $\mathrm{C}$ is the origin of coordinate system 0 $\left(\underline{r}_{C}=\underline{0}\right)$. It has to be reached directly after reaching point $\mathrm{B}$ by telescoping the magazine holder.

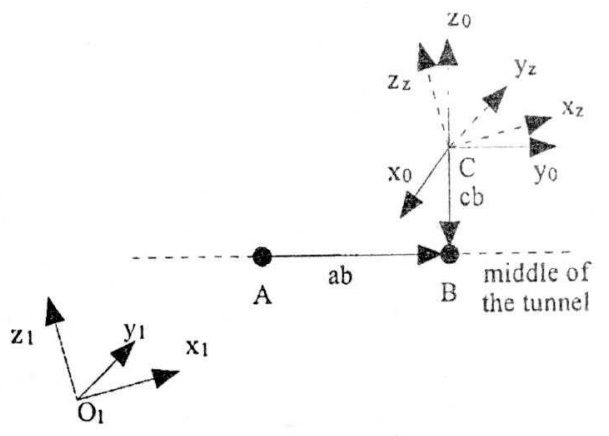

Figure 8: Reference points

If the points have been reached in the described way, the measuring systems supply the following values:

$$
{ }^{1} \underline{r}_{A}=f(\underline{q}) \quad{ }^{1} \underline{r}_{B}=f(\underline{q}) \quad{ }^{1} \underline{r}_{C}=f(\underline{q})
$$

The intermediate coordinate systeme $\mathrm{z}$ has the same orientation as the vehicle-fixed coordinate systeme 1 , but it has an offset of the vector ${ }^{1} \underline{r}_{\mathrm{C}}$. Therefore, it is clear that

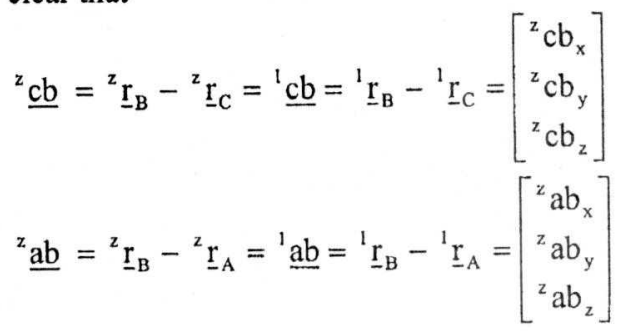

${ }^{\mathrm{z}} \mathrm{cb}_{\mathrm{x}},{ }^{\mathrm{z}} \mathrm{cb}, \mathrm{y},{ }^{\mathrm{z}} \mathrm{cb},{ }_{\mathrm{z}},{ }^{\mathrm{z}} \mathrm{ab},{ }_{\mathrm{x}},{ }^{\mathrm{z}} \mathrm{ab} \mathrm{b}_{\mathrm{y}},{ }^{\mathrm{z}} \mathrm{ab}_{\mathrm{z}}$ are given by the measuring systems of the axis coordinates $\underline{q}$.

In coordinate system 0 of the drilling scheme we get

${ }^{0} \mathrm{~A}=\left[\begin{array}{c}0 \\ -{ }^{0} \mathrm{ab} \\ { }^{0} \mathrm{cb}\end{array}\right], \quad{ }^{0} \mathrm{~B}=\left[\begin{array}{c}0 \\ 0 \\ { }^{0} \mathrm{cb}\end{array}\right], \quad{ }^{0} \mathrm{C}=\left[\begin{array}{l}0 \\ 0 \\ 0\end{array}\right]$.

$\underline{\mathrm{cb}}$ and $\underline{\mathrm{ab}}$ are given by

$\underline{0} \underline{\mathrm{cb}}=\left[\begin{array}{c}0 \\ 0 \\ { }^{0} \mathrm{cb}\end{array}\right], \quad \underline{\mathrm{ab}}=\left[\begin{array}{c}0 \\ 0 \mathrm{ab} \\ 0\end{array}\right]$.

${ }^{0} \mathrm{cb}$ is given by telescoping the magazine holder. It is the difference between $\mathrm{q}_{6}$ when reaching point $\mathrm{B}$ and $\mathrm{q}_{6}$ when reaching point $\mathrm{C}$. ${ }^{0} \mathrm{ab}$ is unknown. 
The ${ }^{0} \mathrm{x}_{1^{-}},{ }^{0} \mathrm{y}_{1^{-}}$and ${ }^{0} \mathrm{z}_{1^{-}}$-axis in the drilling scheme (coordinate system 0 ) result from the matrix ${ }^{0} \underline{\underline{R}}_{z}$ :

$$
\begin{aligned}
& { }^{0} \underline{\mathrm{R}}_{\mathrm{z}}={ }^{0} \mathrm{R}_{1}=\left[\begin{array}{lll}
\alpha^{\prime} & \alpha^{\prime \prime} & \alpha^{\prime \prime \prime} \\
\beta^{\prime} & \beta^{\prime \prime} & \beta^{\prime \prime \prime} \\
\gamma^{\prime} & \gamma^{\prime \prime} & \gamma^{\prime \prime \prime}
\end{array}\right] \\
& { }^{0} \mathrm{x}_{1}-\operatorname{axis} \uparrow \uparrow \uparrow^{0} \mathrm{z}_{1} \text {-axis } \\
& { }^{0} y_{1} \text { - axis }
\end{aligned}
$$

With the scalar product the angle between two vectors (with regard to different coordinate systems) can be compared:

$$
\begin{aligned}
& \underline{{ }^{0} \mathrm{cb}} \cdot{ }^{0} \underline{\mathrm{x}}_{1}=\left[\begin{array}{c}
0 \\
0 \\
{ }^{0} \mathrm{cb}
\end{array}\right] \cdot\left[\begin{array}{c}
\alpha^{\prime} \\
\beta^{\prime} \\
\gamma^{\prime}
\end{array}\right]={ }^{2} \underline{b c} \cdot{ }^{1} \underline{x}_{1}=\left[\begin{array}{c}
{ }^{2} \mathrm{cb}_{\mathrm{x}} \\
{ }^{2} \mathrm{cb}_{y} \\
{ }^{2} \mathrm{cb}_{z}
\end{array}\right] \cdot\left[\begin{array}{l}
1 \\
0 \\
0
\end{array}\right] \\
& \underline{{ }^{0} \mathrm{cb}} \cdot{ }^{0} \underline{y}_{-1}=\left[\begin{array}{c}
0 \\
0 \\
{ }^{0} \mathrm{cb}
\end{array}\right] \cdot\left[\begin{array}{c}
\alpha^{\prime \prime} \\
\beta^{\prime \prime} \\
\gamma^{\prime \prime}
\end{array}\right]={ }^{\mathrm{z}} \underline{\mathrm{bc}} \cdot{ }^{1} \underline{y}_{1}=\left[\begin{array}{l}
{ }^{\mathrm{c}} \mathrm{cb}_{\mathrm{x}} \\
{ }^{\mathrm{z}} \mathrm{cb}_{\mathrm{y}} \\
{ }^{\mathrm{z}} \mathrm{cb}_{\mathrm{z}}
\end{array}\right] \cdot\left[\begin{array}{l}
0 \\
1 \\
0
\end{array}\right] \\
& { }^{0} \underline{\mathrm{cb}} \cdot{ }^{0} \underline{\underline{z}}_{1}=\left[\begin{array}{c}
0 \\
0 \\
{ }^{0} \mathrm{cb}
\end{array}\right] \cdot\left[\begin{array}{c}
\alpha^{\prime \prime \prime} \\
\beta^{\prime \prime \prime} \\
\gamma^{\prime \prime \prime}
\end{array}\right]={ }^{z} \underline{\mathrm{cb}} \cdot{ }^{\prime} \underline{z}_{1}=\left[\begin{array}{c}
{ }^{2} \mathrm{cb}_{\mathrm{x}} \\
{ }^{2} \mathrm{cb}_{\mathrm{y}} \\
{ }^{2} \mathrm{cb}_{\mathrm{z}}
\end{array}\right] \cdot\left[\begin{array}{l}
0 \\
0 \\
1
\end{array}\right]
\end{aligned}
$$

These three equations lead to the solutions for $\gamma^{\prime}, \gamma^{\prime \prime}$ and $\gamma^{\prime \prime \prime}$.

The solutions for $\alpha^{\prime}, \alpha^{\prime \prime} \ldots \beta^{\prime \prime \prime}$ are given by

$$
\begin{aligned}
& { }^{0} \underline{\mathrm{bc}}={ }^{0} \underline{\underline{\mathrm{R}}} \cdot{ }^{2}{ }^{2} \underline{\mathrm{b} c}, \quad \quad \underline{\mathrm{ab}}={ }^{0} \underline{\mathrm{R}} \cdot \mathrm{z} \cdot{ }^{2} \underline{\mathrm{ab}} \\
& \alpha^{\prime 2}+\alpha^{1,2}+\alpha^{1122}=1, \quad \alpha^{\prime 2}+\beta^{\prime 2}+y^{\prime 2}=1 \\
& \alpha^{\prime \prime 2}+\beta^{\prime \prime 2}+y^{\prime \prime 2}=1, \quad \alpha^{\prime \prime 12}+\beta^{\prime \prime 12}+y^{\prime \prime 12}=1
\end{aligned}
$$

There are 16 solutions for the rotation matrix ${ }^{0} \underline{R}_{2}$.

Based on the following conditions these solutions can be minimized to one solution.

- The three axes form a right-hand system, i.e. all three axes are perpendicular to each other and correspond to the $\mathrm{x}-, \mathrm{y}$ - and $\mathrm{z}$-direction.

- If point $A$ is closer to the drilling vehicle than point $\mathrm{B}$ then ${ }^{\mathrm{O}} \mathrm{ab}>0$ else ${ }^{0} \mathrm{ab}<0$.

- The rotation matrix can also be determined by using Kardan angles (rotation of the z-, $y$ - and $x$-axis). Due to the steric conditions of the tunnel the absolute value of the three angles is less than $45^{\circ} \operatorname{abs}(\gamma$, $\beta, \alpha)<45)$.

The translation vector runs

$$
{ }^{0} \underline{\mathrm{r}}_{0} \mathrm{O}_{1}=-{ }^{0} \underline{\mathrm{R}}_{1} \cdot{ }^{1} \underline{\mathrm{r}}_{\mathrm{C}}
$$

\section{Summary}

This paper deals the kinematic equations of a drilling vehicle in the winning of salt. A software module based on these eqations is integrated into the control to increase the accuracy of drilling in the manual operation as well as in the semi-automated fixed-point operation.

\section{Acknowledgement}

We would like to thank the firms Kali \& Salz $\mathrm{GmbH}$, Germany and BTZ Dietlas GmbH, Germany for the instruction of this interesting application of our theoretical knowledges.

\section{REFERENCES}

[1] H. Kerle, R. Pittschellis. "Einfuihrung in die Getriebelehre." B.G. Teubner Stuttgart. 1998

[2] H. Rieseler. "Roboterkinematik - Grundlagen, Invertierung und symbolische Berechnung." Fortschritte der Robotik 16. Vieweg-Verlag. 1992. 